Technological University Dublin

DƯBLIN

ARROW@TU Dublin

2009-01-01

\title{
Holographic Recording in Charged Photopolymerisable Nanocomposites
}

\author{
Temenujka Yovcheva \\ University of Plovdiv "Paissi Hilendarski", Bulgaria \\ Ivanka Vlaeva \\ Bulgarian Academy of Sciences \\ Simeon Sainov \\ Bulgarian Academy of Sciences
}

See next page for additional authors

Follow this and additional works at: https://arrow.tudublin.ie/cieocon2

Part of the Optics Commons

\section{Recommended Citation}

Yovcheva, T., Vlaeva, I. \& Sainov, S. (2009). Holographic recording in charged photopolymerisable nanocomposites. Conference Proceedings International Commission for Optics Topical Meeting on Emerging Trends and Novel Materials in Photonics, vol. 1288, pg. 39-42. doi:10.1063/1.3521366

This Conference Paper is brought to you for free and open access by the Centre for Industrial and Engineering Optics at ARROW@TU Dublin. It has been accepted for inclusion in Conference Papers by an authorized administrator of ARROW@TU Dublin. For more information, please contact arrow.admin@tudublin.ie, aisling.coyne@tudublin.ie,gerard.connolly@tudublin.ie.

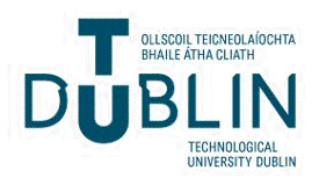




\section{Authors}

Temenujka Yovcheva, Ivanka Vlaeva, Simeon Sainov, Izabela Naydenova, Vincent Toal, and Svetlana Mintova 
2009-01-01

\section{Holographic recording in charged photopolymerisable nanocomposites}

Temenujka Yovcheva

University of Plovdiv "Paissi Hilendarski", Bulgaria

Ivanka Vlaeva

Bulgarian Academy of Sciences

Simeon Sainov

Bulgarian Academy of Sciences

Izabela Naydenova

Dublin Institute of Technology, izabela.naydenova@dit.ie

Vincent Toal

Dublin Institute of Technology, vincent.toal@dit.ie

See next page for additional authors

\section{Recommended Citation}

T. Yovcheva, I Vlaeva, S. Sainov, I. Naydenova, V. Toal, S. Mintova, Holographic recording in charged photopolymerisable nanocomposites, Conference proceedings of the International commission for Optics Topical meeting on Emerging trends and novel materials in photonics, v.1288, 39-42, 2009. 


\section{Authors}

Temenujka Yovcheva, Ivanka Vlaeva, Simeon Sainov, Izabela Naydenova, Vincent Toal, and Svetlana Mintova 


\title{
Holographic recording in charged photopolymerisable nanocomposites
}

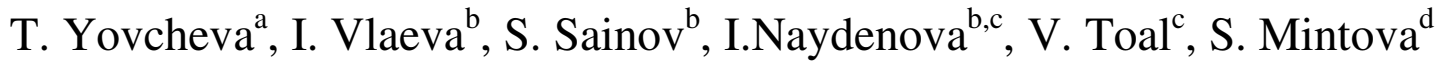 \\ ${ }^{a}$ Department of Experimental Physics, University of Plovdiv “Paissi Hilendarski”, 24 Tzar Assen Str. 4000, Plovdiv, \\ Bulgaria \\ ${ }^{b}$ Central Laboratory of Optical Storage and Processing of Information, Bulgarian Academy of Sciences, Bl. 101, \\ Acad. G. Bonchev Str., 1113 Sofia, Bulgaria \\ ${ }^{c}$ Centre for Industrial and Engineering Optics, School of Physics, Dublin Institute of Technology, Kevin Street, \\ Dublin 8, Ireland \\ ${ }^{d}$ Laboratoire Catalyse \& Spectrochimie (LCS), ENSICAEN - Université de Caen - CNRS, 6, boulevard du Maréchal \\ Juin, 14050 Caen Cedex, France
}

\begin{abstract}
The holographic recording properties of charged zeolite containing photopolymerisable nanocomposites were studied. Photopolymer samples doped with pure silica MFI-type zeolite nanoparticles were charged using corona discharge. The holographic properties of the nanocomposites were characterised in real time using the Stetson geometry of recording. The influence of the type of charge - positive or negative on the dynamics of holographic recording and the final diffraction efficiency was studied.
\end{abstract}

Keywords: photopolymerisable nanocomposites, holographic recording, zeolite nanoparticles, photopolymers.

PACS: 42.70.Ln, 42.40.-I, 42.70.Jk, 42.40.Pa

\section{INTRODUCTION}

Self - processing photopolymers have a large number of different applications due to their versatile properties as holographic recording materials. A significant effort has been directed towards the development of photopolymers for holographic data storage [1, 2], holographic sensors [3], holographic optical elements [4] and display holograms [5]. The Centre for Industrial and Engineering Optics has been developing acrylamide based photopolymers for the last decade [6-8]. The main parameters requiring improvement in these types of photopolymers are their dynamic range and their mechanical stability during the holographic recording. Recently we have successfully used zeolite nanoparticles as dopants in order to increase the dynamic range and lower the shrinkage in acrylamide-based photopolymers [9]. The advantages of using zeolite nanoparticles in colloidal form are their stability in water suspension: they have the same $\mathrm{pH}$ as the photopolymer and can be synthesized with different shape, size and chemical composition. Depending on the chemical composition and types of the structure, the zeolites will exhibit variable refractive index. Among the different types of zeolite nanoparticles used for doping of photopolymers, the pure silica MFI (Si-MFI) has shown the best results [9]. Having in mind that the zeolites are negatively surface charged it is expected to be an appropriate dopant for photopolymers [10].

We studied the effect of the charging of the photosensitive layers on their holographic recording properties. The charging was achieved by exposure to corona discharge. Different types of charges - positive and negative were deposited on the layer surfaces. It was observed that their presence influences the diffraction efficiency of recording.

\section{THEORY}

When a sample surface contacts some medium (gas or liquid), adsorption and desorption processes of medium particles occur [11]. In the case of a dynamic equilibrium between the two processes, there is an equilibrium concentration for the adsorbed particles. Some of these particles interact electrically with the adsorbent surface (physical adsorption), while others form chemical bonds with molecules from adsorbent surface. In the latter case, oxygen is very active. The equilibrium concentration of adsorbed particles may change under the influence of various external factors such as temperature, pressure, and electric field. 
When polymers layers are subjected to corona discharge in air, various ions and ion groups are created. Some of the ions recombine on the surface of the material, giving rise to chemical changes in it, while the remaining ions penetrate into the bulk of the materials, where their charge becomes trapped [12]. It was demonstrated [13, 14] that a stable surface charge but not a volume charge is formed at relatively mild corona charging parameters like room temperature $\left(20^{\circ} \mathrm{C}\right)$ and $5 \mathrm{kV}$ corona voltage. In this case during the charging samples one can assume that only adsorption and a desorption processes of charged particles take place. These particles are accelerated by the electric field of the corona and interact with the surface of the samples. The authors in [15] have ascertained that ac air corona is characterized by high concentrations of $\mathrm{O}, \mathrm{HO}_{2}, \mathrm{H}_{2} \mathrm{O}_{2}, \mathrm{OH}$ and $\mathrm{O}_{3}$ groups. At the same time, the corona discharge forms water-soluble, low-molecular-weight, oxidized materials (LMWOM). According to [16], if a positive corona occurs in air, the prevailing ions are of the type $\left(\mathrm{H}_{2} \mathrm{O}\right)_{n} \mathrm{H}^{+},\left(\mathrm{H}_{2} \mathrm{O}\right)_{n} \mathrm{NO}^{+}$and $\left(\mathrm{H}_{2} \mathrm{O}\right)_{n}\left(\mathrm{NO}_{2}\right)^{+}$. If negative corona occurs in air, the most important ions are the $\left(\mathrm{H}_{2} \mathrm{O}\right)_{n} \mathrm{CO}_{3}^{-}$and $\mathrm{CO}_{3}^{-}$ions.

Positively or negatively charged oxygen-containing ions deposited on the sample surface, during the charging process, generate a constant electric field in the sample volume. This additional electric field can induce additional charges or cause orientation of charged structures (such as zeolite nanoparticles) in the volume.

Previous studies of the holographic recording process in acrylamide based photopolymers [6-9] reveal that this process leads to a spatially modulated refractive index due to - monomer to polymer conversion, concentration driven monomer diffusion from the dark to the bright fringes, short polymer diffusion in opposite direction and, in the case of zeolite doped layers, facilitates the special redistribution of the zeolite nanoparticles. The rise of the refractive index modulation can be observed in real time by measuring the diffraction efficiency of the recorded volume phase holographic gratings.

\section{EXPERIMENTAL}

\section{Materials}

The holographic recording material consists of a soft polymer matrix containing porous zeolite nanoparticles of $60 \mathrm{~nm}$ size with concentrations in the range from $0 \mathrm{wt} . \%$ to $10 \mathrm{wt} \%$. $40 \mu \mathrm{m}$ thick layers are obtained by casting the photopolymer nanocomposite solution on glass substrates. The photopolymer matrix contains two monomers acrylamide and N,N Methylene bisacrylamide, an initiator - triethanolamine, a binder - polyvinyl alcohol and a dye sensitiser Erythrosin B.

\section{Charging of the samples}

The charging of the samples was carried out using a point-to-plane three-electrode corona discharge system. The system consisting of a corona electrode (needle), a grounded plate electrode and a grid placed between them is represented in Fig. 1. The distance between the grounded plate electrode and the grid was $10 \mathrm{~mm}$; the distance from the grid to the corona electrode was $7 \mathrm{~mm}$. The samples were placed on the grounded plate electrode and were charged for $3 \mathrm{~min}$ at $\mathrm{RH} 45 \%, 23^{\circ} \mathrm{C}$ and atmospheric pressure of $101.3 \mathrm{kPa}$. Positive or negative $5 \mathrm{kV}$ voltages were applied to the corona electrode. A $1 \mathrm{kV}$ voltage with the same polarity was supplied to the grid. Introducing a grid between the corona electrode and sample limits the sample surface potential to that of the grid and produces a more uniform distribution of charge on the sample surface.

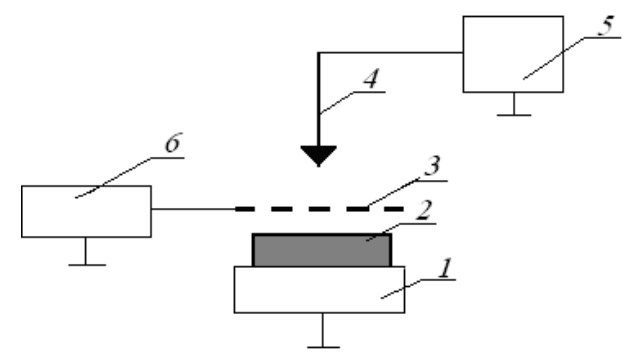

FIGURE 1. Experimental set up for corona charging: 1 - Grounded electrode; 2 - Sample holder; 3 - Grid - $\pm 1 \mathrm{kV} ; 4$ - Corona electrode (needle) - $\pm 5 \mathrm{kV} ; 5$ - Bias supply to the corona electrode; 6 - Bias supply to the grid. 


\section{Holographic recording set-up}

The experimental set up is shown in Fig. 2. The light from a 532nm solid state laser was expanded and split into two recording beams which were then directed towards a total internal reflection prism (TIR) (as shown in Fig.2) in contact with a glass substrate. The substrate side facing the TIR prism was index matched by a high refractive index liquid - benzyl alcohol; the photopolymerisable nanocomposite was cast on the other side of the substrate. The recorded holographic grating was probed by a $633 \mathrm{~nm}$ probe beam. The layer is not sensitive to this wavelength. The recording intensity was $25 \mathrm{~mW} / \mathrm{cm}^{2}$ and the total exposure was $550 \mathrm{~mJ} / \mathrm{cm}^{2}$.

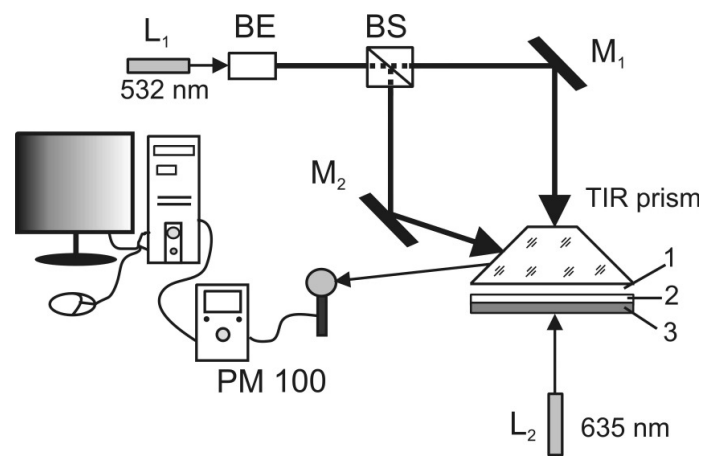

FIGURE 2. L1 - $60 \mathrm{~mW} / 532 \mathrm{~nm}$ semiconductor laser; L2 - $1.5 \mathrm{~mW} / 635 \mathrm{~nm}$ semiconductor laser; BE - beam expander; BS beam splitter; M1,2 - mirrors; TIR prism - Total internal reflection prism of refractive index 1.522; 1 - Benzyl alcohol; 2 - glass substrate; 3 - Si-MFI nanozeolite doped samples; PM 100 - power meter.

\section{RESULTS AND DISCUSSION}

The results in Fig. 3 show a comparison of the diffraction efficiency dynamics in undoped and doped layers. It is seen that the addition of nanoparticles leads to an increase in the diffraction efficiency most probably due to nanoparticle redistribution. The optimum concentration of the nanoparticles was $2.5 \mathrm{wt} \%$. Because the nanoparticles are porous and their density is relatively low $\left(1.78 \mathrm{~g} / \mathrm{cm}^{3}\right)$ the volume fraction of the nanoparticles in the photosensitive layer corresponding to this concentration is in the order of $13.5 \%$.

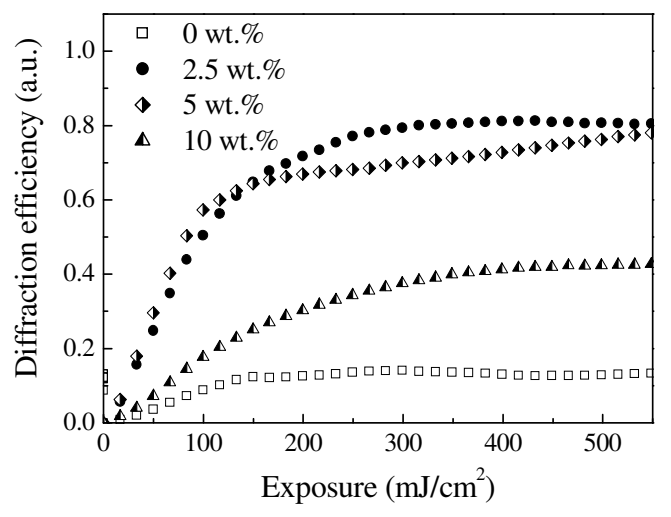

FIGURE 3. Diffraction efficiency of undoped, $2.5 \mathrm{wt} . \%$ doped, $5 \mathrm{wt} . \%$ doped and $10 \mathrm{wt} . \%$ doped layers.

The influence of the electrical charging on undoped and 2.5wt.\% doped layers can be seen in Fig. 4. 

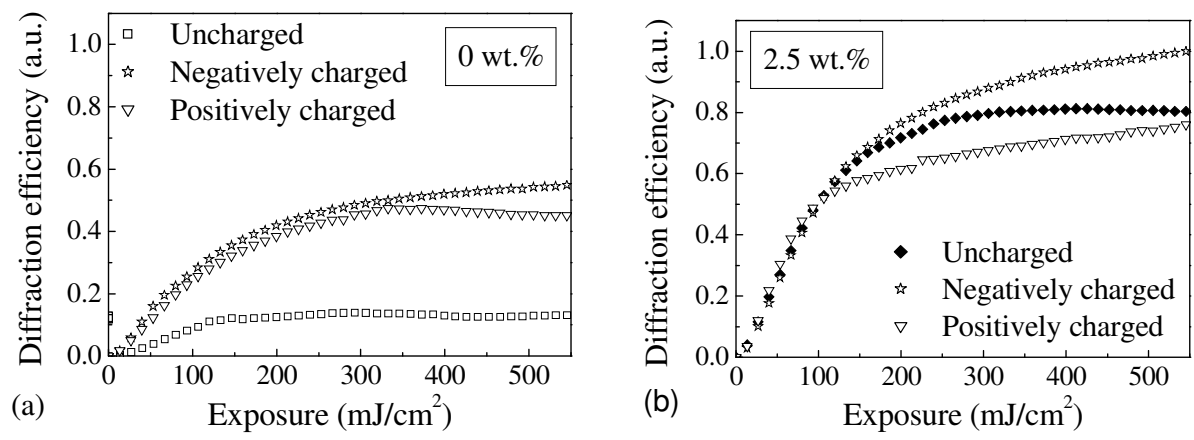

FIGURE 4. Influence of the corona charging on the real time diffraction efficiency in:

(a) undoped layers and (b) $2.5 \mathrm{wt} . \%$ doped layers.

It is seen that both undoped and doped layers are influenced by the corona charging. During the charging process positively or negatively charged ions, created in the corona discharge, are deposited on the sample surface. The observed differences in the diffraction efficiency dependencies could be explained by the difference in the electric field created by the corona discharge. In doped layers there is a superposition of two electrostatic fields. The first field (also present in undoped layers) is due to deposition of corona discharge ions on the layers surface and the second (not present in undoped layers) is created by the zeolite carried charge distributed in the sample volume.

\section{CONCLUSIONS}

In summary, there is an optimal concentration of $(2.5-5)$ wt.\% of zeolite Si-MFI nanoparticles for which maximum diffraction efficiency is achieved during holographic recording in the nanocomposites layers. Negative corona discharge is preferable for samples treatment before holographic recording. It was observed that the prerecording exposure to corona discharge of undoped layers improves their efficiency of recording.

\section{ACKNOWLEDGMENTS}

This study was supported by the Science Foundation Ireland grant N 065/RFP/PHY085. The authors would like to acknowledge the COST Action MP0604 for funding Dr. T. Yovcheva's STSM to the Dublin Institute of Technology.

\section{REFERENCES}

1. "Holographic Data Storage", Eds. H. Coufal, D. Psaltis, G. Sincerbox (Eds.), Springer (2000).

2. http://www.inphase-technologies.com/; http://www.aprilisinc.com/

3. I. Naydenova, R. Jallapuram, V. Toal and S. Martin, Appl. Phys. Lett. 92, p. 031109 (2008).

4. E. Mihaylova, I. Naydenova, S. Martin and V. Toal, Appl. Opt. 43, p. 2439-2442 (2004).

5. C. Meka, R. Jallapuram, I. Naydenova, S. Martin and V. Toal, Development of a panchromatic acrylamide based photopolymer for multicolour reflection holography" accepted for publication in Appl. Opt 2010.

6. S. Martin, C.A. Feely and V. Toal, Appl. Optics 36, 5757-5768 (1997).

7. I. Naydenova, R. Jallapuram, S. Martin, R. Howard and V. Toal, Appl. Opt. 43, p. 2900-2905 (2004).

8. R. Jallapuram, I. Naydenova, S. Martin, R. Howard and V. Toal, Appl.Opt., 47 (2), p. 206-212 (2008).

9. I. Naydenova and V. Toal, "Nanoparticle Doped Photopolymers for Holographic Applications" in Ordered Porous Solids: Recent Advances and Prospects, edited by V. Valtchev, S. Mintova and M. Tsapatsis, UK: Elsevier 2008, pp.559-590.

10. R. Szostak, Molecular Sieves: Principles of synthesis and identification, London-Weinheim-NY-Tokyo-Melbourne-Madras: Blakie Academic \& Professional, 1998, 359 pages.

11. W. Adamson and P. Alice, Gast Physical Chemistry of Surfaces, 6th Edition, John Wiley \& Sons, Inc., 1997, 808 pages.

12. B. Hilczer and J. Malecki, Electrets. Amsterdam: PWN-Polish Scientific Publisher, 1986, 166 pages.

13. A. Mellinger, F. C. Gonzales, R. Multhaupt, L. F. Santos and R. M. Faria, Proc. 11-th Intern. Symp. Electrets, Melbourne, Australia, 2002, pp.7-10.

14. T. Yovcheva, G. Mekishev and A. Marinov, J. Phys.: Cond. Matter 16, 455- (2004).

15. M.Strobel, V.Jones, C.S.Lyons, M.Ulsh, M.J.Kushner, R.Dorai and M.C.Branch, Plasmas and Polymers 8, 61-95, (2003).

16. J.A.Giacometti and O.N.Oliveira, IEEE Trans. Electr. Insulation 27, 924-943 (1992). 